THE KURUME MEDICAL JOURNAL Vol. 18, No. 3, 1971

\title{
THREE CASES OF SCHIZOPHRENIA TREATED WITH L-DOPA
}

\author{
KAZUTOYO INANAGA, MASACHIKA OSHIMA \\ AND HISAYUKI TACHIBANA \\ Department of Neuropsychiatry, Kurume University \\ School of Medicine, Kurume, Japan \\ KENICHI NAKAMURA \\ Nakamura Hospital, Fukuoka, Japan \\ KYOZO KOKETSU \\ Department of Physiology, Kurume University \\ School of Medicine, Kurume, Japan
}

(Received for publication March 21, 1971)

\begin{abstract}
In three cases of schizophrenia, ill for three - six years with no sign of remission under various psychopharmacotherapies, L-Dopa was used with the major tranquilizers which had previously been used. Subsequently, remarkable recovery was noted. The tentative dosage of L-Dopa in this research was 400-1200 mg per day. Hallucination and thought disorder had disappeared as well as apathy and lack of spontaneity. In one case, upon the suspension of L-Dopa, the patient's symptoms exacerbated. Continuous administration of L-Dopa is necessary for the improvement of the symptoms.
\end{abstract}

In recent years the role of dopamine in the function of the extrapyramidal system has become evident (Bertler and Rosengren ${ }^{5)}, 1959$; Sano et al. ${ }^{16)}, 1959$; Carlsson ${ }^{11)}$, 1959 ; Ehringer and Hornykiewic ${ }^{13)}, 1960$ ). In Parkinson's disease, it has been found that in neostriatum and substantia nigra there is a practical disappearance of dopamine (Ehringer and Hornykiewicz ${ }^{13)}$, 1960) and of homovanillic acid (Bernheimer and Hornykiewicz ${ }^{4}$, 1964 ; Gottfries et al. ${ }^{14)}$, 1965).

The treatment of parkinsonian patients with L-Dopa has been tried on the basis of these evidences (Barbeau et al. ${ }^{1)}$, 1962 ; Birkmayer and Hornykiewicz ${ }^{6)}$, 1962). Further study has indicated that L-Dopa antagonizes reserpine-induced parkinsonism and the extrapyramidal symptoms of Parkinson's disease (Degkwitz et al. ${ }^{12)}, 1960$ ). There is a significant increase of dopamine and homovanillic acid (HVA) urinary excretion when schizophrenics, treated with large therapeutic doses of chlorpromazine and haloperidol, show marked extrapyramidal symptoms (Bruno et al. ${ }^{8}$, 1963 ; Bruno and Allegranza $\left.{ }^{7}, 1965\right)$.

They discussed whether L-Dopa antagonized chlorpromazine- or haloperidol-induced parkinsonism in schizophrenic patients. In this experiment the effect of a single $i$. v. injection of $2 \mathrm{mg} / \mathrm{kg}$ L-Dopa on the extrapyramidal 
symptomatology of 40 schizophrenics taking chlorpromazine or haloperidol at large therapeutic doses was investigated. Results were favorable but uneven and transient. Improvement was observed on akinesia, regidity, akathisia, dystonic reactions, tremor, in that order.

The purpose of this study is to investigate the changes of psychic conditions in schizophrenic patients treated with L-Dopa together with major tranquilizers and it was found that relatively small amount of L-Dopa combined with other types of major tranquilizers was effective for the treatment of psychotic conditions of the patients.

\section{RESULTS}

CASE 1: J. H. Female. 26 yrs.

Chief Complaint: She was seclusive and idle. She does not talk much to others. She talks and laughs to herself.

Family History: None.

Medical History: None.

Personality: She is fond of being alone, quiet and gentle in nature.

Present Illness: After graduating from High School, she worked at a clerical job at her father's hospital. Her grades were fairly high. Because of domestic circumstances, she was forced to give up going to college unwillingly. She greatly regretted it. About August, 1967, she became mute and absentminded, and very neglectful in performing her clerical work. She got up late. She felt as if hospital employees treated her badly, made insinuations to her, and said many spiteful things to her concerning salaries and improvement of working conditions. She was annoyed and would not speak to anyone. But she was not so severely disturbed that she could not lead an ordinary life. She was engaged in her house work and clerical work at the hospital just as before. In January, in addition to the above-mentioned symptoms, she sometimes discontinued her work and shut herself in her room. She did not talk much with her family. Though they tried to communicate with her, she did not respond rationally. Her face appeared vacant. She complained of the following: Her train of thought was suddenly interrupted, people were able to read her mind, and people around her forced her to do and think things. People treated badly, watched her, spoke ill of her, and made insinuations against her. Her parents thought that these symptoms resulted from her slovenly, undisciplined habits. So they sent her to her aunt's house and forced her to lead a regular life. Gradually, however, she showed a pronounced tendency to autism. She laughed incongruously, talked to herself, and suddenly spoke of unrelated matters in the midst of her conversations.

In April 1969, she was compelled to help with house work, but never completed it, and, what is worse, never did it well. She retreated in her room. She did not leave the room unless her family requested it. After that she lodged alone in Fukuoka city and went to knitting school. She neither cleaned her room, nor put away her bedding. She remained in her room without going to school.

In January 1970, she did not pay any attention to her own appearance, nor did she bathe. She shut herself in her room and locked the door, saying that she was being stalked by spies. Monologia and inane incongruous laughter became apparent. She was admitted to Kurume University Hospital on March 18.

Psychotic conditions at her admission are shown in the Fig. 1: Apathy, 


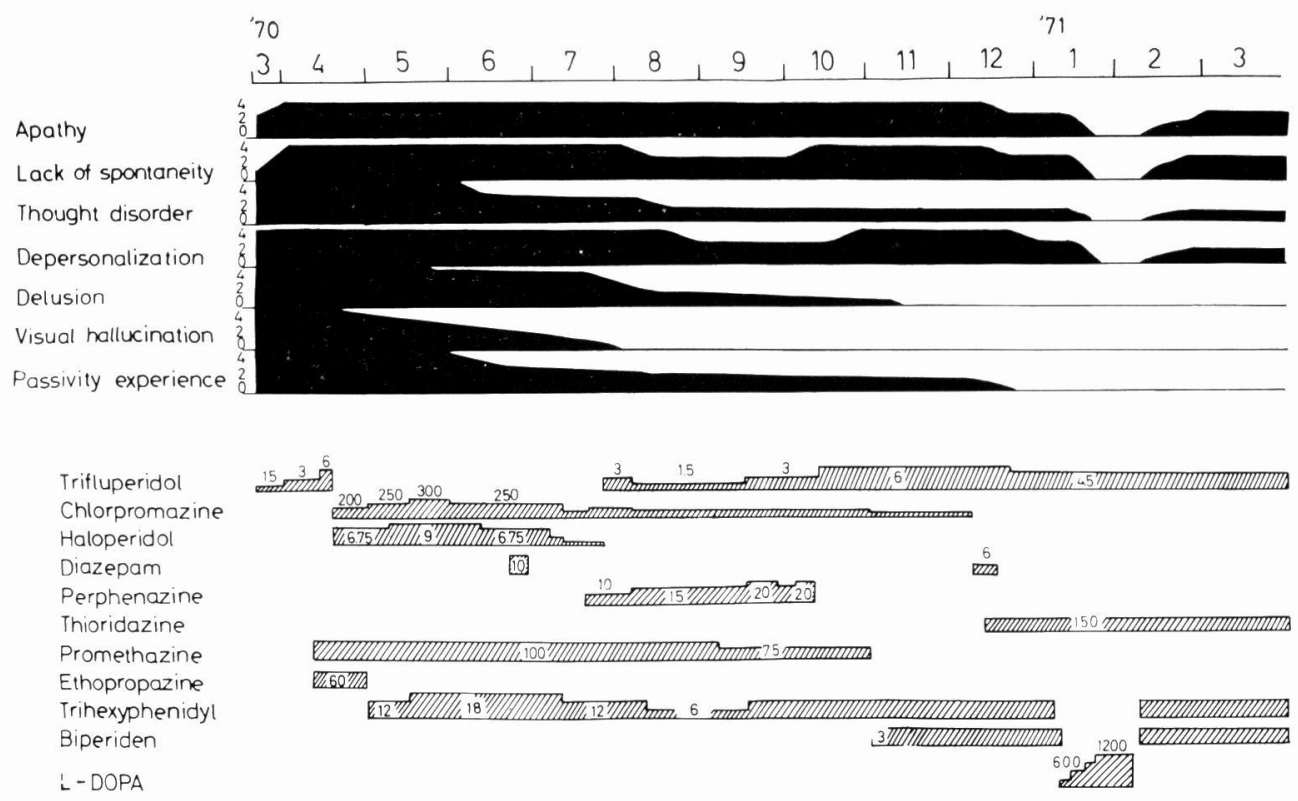

Fig. 1

lack of spontaneity, thought disorder (thought deprivation, broadcasting and blocking of thought), disturbance of self (depersonalization and passivity feeling), delusion (hypochondriac delusion, delusion of reference and delusion of persecution), auditory hallucination, inane incongruous laughter, monologia etc. The treatment was started with a single administration of trifluperidol, then chlorpromazine and haloperidol at the same time, diazepam together with chlorpromazine and haloperidol, perphenazine together with chlorpromazine and trifluperidol, and thioridazine with trifluperidol. Auditory hallucination, inane incongruous laughter and monologia disappeared after a short period (four months). She said that she did not suffer from delusion and passivity feeling in about seven-nine months. But in this case, thought disorder (blocking of thought only), lack of spontaneity, depersonalization and apathy were never decreased. L-Dopa 300 $\mathrm{mg}$ together with thioridazine $150 \mathrm{mg}$ and trifluperidol $4.5 \mathrm{mg}$ was administered, and L-Dopa was increased in 300 $\mathrm{mg}$ increments each four days. At 900 mg L-Dopa, she was less apathetic and she had an increase of spontaneity, which did not occur with the administration of thioridazine $150 \mathrm{mg}$ and trifluperidol $4.5 \mathrm{mg}$. She went bowling and willingly took part in recreation. She became merry and lively. She no longer slept during the day. She watched television and was interested in chattering with other patients. She said that she no longer experienced depersonalization and disturbance of thought. She said that during her abnormal experiences she heard various awful things, and unpleasant voices like in bad dream. In February 10, 1971, she was given an anti-parkinsonian drug, instead of L-Dopa. Subsequently she gradually showed amimia, mutism and slowness of activity. 
CASE 2 : S. K. Male. 24 yrs. A worker. Schizophrenia.

Family History: Father died of pulmonary tuberculosis. He is the youngest child of seven brothers. The family has no special hereditary factor.

Personality : He is a mute, sombre and quiet man in nature. He does not associate with others.

Present Illness: He got a job at an electric industrial company in Tokyo in 1964. Soon he suffered from insomnia and anxiety. He was diagnosed to be somewhat neurotic. He returned to Fukuoka in May, and was admitted to a private hospital. He left the hospital in July with much improved. He began to work in publishing company in Tokyo.
But three months later he was readmitted to the former hospital. After leaving the hospital in 1965, he worked in Osaka for a while. He was sent to another private hospital in December in the same year and received a hospital treatment for thirteen months. After being discharged from this hospital, he lived in his brother's home in Kumamoto. He glared his mother, suddenly jumped at his brother and mother, beated them, kicked them, and called them aloud, saying that he was a stepson, and that unknown men and women spoke ill of him. He was admitted to the psychiatric ward, Nakamura Hospital in July, 1967. There is not any neurologically abnormal findings.

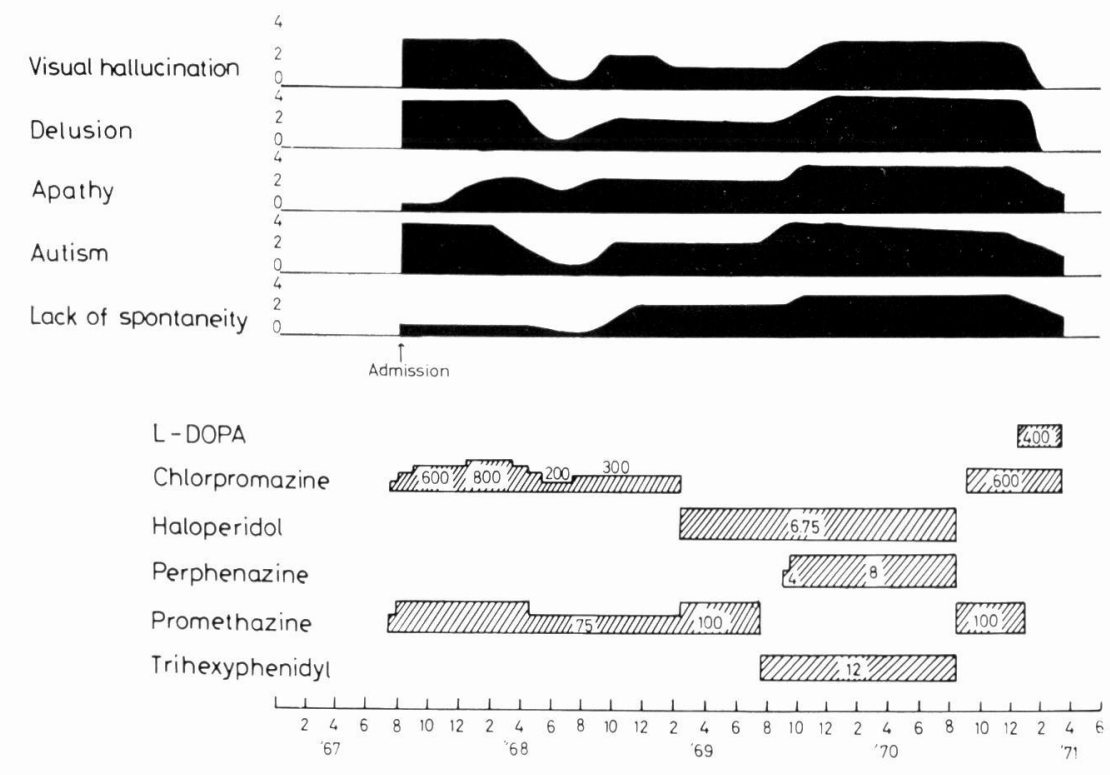

Fig. 2

Psychotic conditions at that time were as follows: His face appeared stiff and he behaved awkward. Auditory hallucination, alienation of thought and delusion of persecution became apparent. $\mathrm{He}$ showed tendency to autism and mutism. Chlorpromazine, haloperidol and perphenazine were given to him, shown in the Fig. 2, after that. In May, 1968, during chlorpromazine treatment, he did not suffer from hallucination and delusion for the present. Autism, lack of spontaneity and apathy were left as they were. Then chlorpromazine was 
decreased gradually. In the end of May, 1968, he stayed in his house for about four days. In the middle of July, 1968, he again appeared rigid. He said that everybody excluded him. Chlorpromazine was increased and after that abovementioned drugs were also used.

Gradually, however, his thought content became incoherent. In December, 1969, he told silly stories, i. e., he did a distinguished service during the 2 nd World War, became an admiral, told his name wrong, he had a wife and children though he was single, and that he was born on June 13, 1887. He suffered from the men's and women's criticizing voices.

In August, 1970, he was given chlorpromazine $600 \mathrm{mg}$ in vain. In December in the same year, promethazine $100 \mathrm{mg}$ which had been given to him together with chlorpromazine was stopped giving: him. Subsequently in December 5, he bagan to suffer from insomnia, hypersalivation, mask-like face, muscular rigidity of jaw and extremities, finger tremor, slurring of speech and anxiety conditions. In seventh of December, when promethazine was readministered, these side-effects all disappeared. In December 15 in the same year, L-Dopa instead of promethazine was administered. He did not show any parkinsonism. In the end of January, 1971, he recovered suddenly from auditory hallucination of eriticizing voices and other abnormal experiences. He appeared to be more natural, increased the spontaneity, and responded rationally.

CASE 3 : T. I. Male. 20 yrs. A student. Schizophrenia.

Family History: He has a sister and a brother. His family does not have any hereditary factor.

Personality: He is mute, sombre and introvert. He does not have many friends.

Present Illness: In April, 1969, when he was admitted to a certain University in $\mathrm{S}$ city, he seldom spoke to others. He felt as if neighbor told him to be fool and talked at him, and woman could read his mind. He did not go to school and stayed in his lodging house idly. July 19, 1969, he was admitted to Naka-

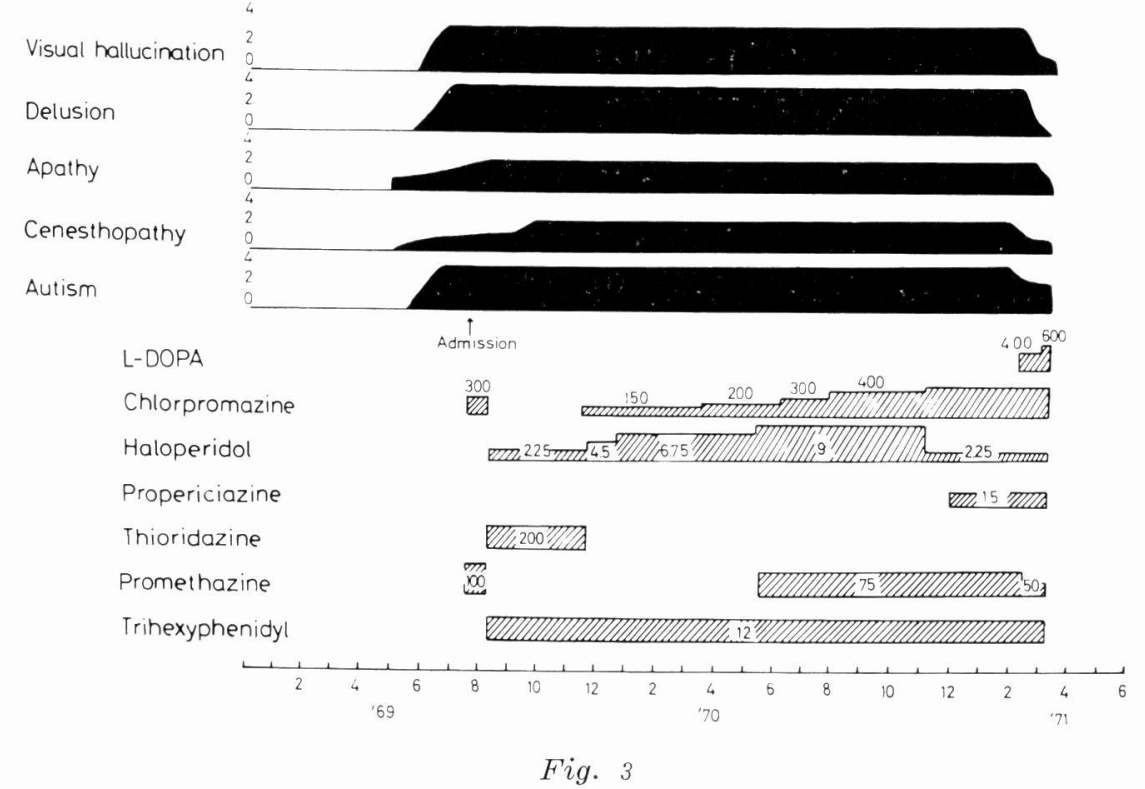


mura Hospital. Any neurologic abnormality was not found in him. Psychotic conditions at that time were as follows: His facial expression was stiff, and action was slow and rigid. He complained that a man could read his mind, and made insinuations against him. He suffered from marked auditory hallucination, thought broadcasting and delusion of persecution. He had the tendency of mutism, autism, and lack of spontaneity. Though chlorpromazine, haloperidol, thioridazine and propericiazine were given, he did not improve. February 17, 1971, L-Dopa $400 \mathrm{mg}$ was added together with chlorpromazine 600 $\mathrm{mg}$, haloperidol $2.25 \mathrm{mg}$ and propericiazine $15 \mathrm{mg}$. Then he told that he suffered from auditory hallucination much less often, with lower voice. In March 3, L-Dopa was increased up to $600 \mathrm{mg}$. In the middle of March, auditory hallucination, delusion of persecution and thought broadcasting disappeared. Even if he suffered from them, it is only once or twice in a day. Though he had been lying bed idly before, he became much more active and willingly took part in cleaning the house with other patients. He appeared comparatively cheerful, and responded smoothly. In February 17, when L-Dopa was added, promethazine which had been administered before was decreased from $75 \mathrm{mg}$ down to $50 \mathrm{mg}$. March 3, when L-Dopa was increased up to $600 \mathrm{mg}$, promethazine was suspended its use. He did not show any parkinsonism.

\section{DISCUSSION}

As L-Dopa is effective in treating Parkinson's disease, effects improving drug-induced parkinsonism should also be anticipated. We administered a small trial dose of L-Dopa to three cases of schizophrenia. These patients had been given various types of major tranqui- lizers for three - six years with no improvement. The observation has proved that L-Dopa has a favorable effect in dealing with not only drug-induced parkinsonism, but also psychotic conditions of the patient. In case 1 , for example, thought disorder, lack of spontaneity, depersonalization, and apathy had completely disappeared ; additionally, remission was noted during L-Dopa administration. When another anti-parkinsonian drug was used instead of L-Dopa, the patient began to suffer from abnormal behavior and psychotic conditions. Hallucination and other abnormal experiences had disappeared in case 2, with the patient becoming more active. Auditory hallucination was reduced, delusion of persecution and thought broadcasting had disappeared, and an improvement in behavior was apparent in case 3 .

To date, L-Dopa has been used for the treatment of Parkinson's disease. Various psychotic conditions have been found as side-effects: 13 cases out of 80 total which Barbeau ${ }^{2)}$ had treated since 1968 suffered from confusion, visual hallucination or vivid dreams. Confusion was very much like toxic delirium. Vivid dreams had sexual and paranoid features. Sleeplessness and agitation were also noted. In the cases with paranoid features, the symptoms which they had been suffering from appeared to become worse. Nine cases showed severe depression with suicidal ideas.

Conversely, L-Dopa was put into use for the treatment of psychotic conditions. Bunney ${ }^{10}$ used L-Dopa for the treatment of depression and found that a daily dose of about $3 \mathrm{~g}$ L-Dopa was quite effective. He mentioned that this was a case of retarded depression, and that three other cases of agitated psychotic depression administered L-Dopa did not show any reaction. Ingvarsson ${ }^{15}$ ) 
stated that $50 \mathrm{mg}$ L-Dopa was effective for the improvement of depressive syndrome in endogenous depression unresponsive to drug therapy for a long time, and that a marginal dose of $22.5 \mathrm{mg}$ a day or $45 \mathrm{mg}$ every other day helped to maintain favorable effects.

We used L-Dopa for schizophrenia because: in schizophrenic patients productive schizophrenic symptoms become rare under psychopharmacotherapy and a comparatively slight apathy and lack of spontaneity, expressed as "dynamic evacuation" (Janzarik), "loss of energy potential" (Conrad), "exhaustion due to psychosis" (Heinrich), and "exhaustion depression" (Kielholz) are recognized ${ }^{3)}$. These are considered to be reversible symptoms. L-Dopa has a mood-elevating and awakening effect definitely improving the above-mentioned symptoms. The three cases of schizophrenia we observed in this research, though they had received various psychopharmacotherapies, commonly showed apathy and lack of spontaneity. These symptoms apparently were improved with the administration of L-Dopa. Visual hallucination, delusion, and other thought disorder had also disappeared.

These observations indicate that a dosage of L-Dopa as used in this research is available for the treatment of schizophrenia. The most important point is knowledge of daily dosage of L-Dopa. Slight differences in the dosage may risk exacerbation of the psychotic symptoms.

In this research L-Dopa was combined with other types of major tranquilizers. Further study should investigate whether L-Dopa alone can be used for the treatment of a certain type of schizophrenia.

L-Dopa's therapeutic effects will clarify the relations between cathecholamine metabolism and pathophysiology of schizophrenia.

\section{ACKNOWLEDGEMENT}

L-Dopa was generously supplied by Kyowa Hakko Co., LTD.

\section{REFERENCES}

1) Barbeau, A., Sourkes, T. L. and Murphy, G. F. : Les catecholamines dans la maladie de Parkinson. In : Monoamines et système nerveux central (Ed. J. De Ajuriaguerra), pp. 247-262, Genève: Georg et Paris : Masson, 1962.

2) Barbeau, A.: L-Dopa therapy in Parkinson's disease. Canad. Med. Ass. J., 101, 791-799, 1969.

3 ) Battegay, R. and Gehring, A.: Influences of neuroleptics on the course of the disease in schizophrenic patients. The Present Status of Psychotropic Drugs. Excerpta Medica Foundation, Amsterdam, pp. 460463, 1969.

4) Bernheimer, H. und Hornykiewicz, O.: Das Verhalten des Dopamine-Metaboliten Homovanillinsäure im Gehirn von normalen und Parkinson Kranken Menschen. Arch. exp. Path. Pharmakol. 247 ; 3051, 964.

$5)$ Bertler, A. and Rosengren, E.: On the distribution in brain of monoamines and of enzymes responsible for their formation. Experientia (Basel) 15, 382-388, 1959.

6 ) Birkmayer, W. and Hornykiewicz, O. : Der L-Dioxyphenylalanin (=L-Dopa). Effekt beim Parkinson-Syndrom des Menschen : Zur Pathogenese und Behandlung der Parinson-Akinese. Arch. Psychiat. Zeitsch. Neurol. 203, 560-574, 1962.

7) Bruno, A. and Allegranza, A. : The effect of haloperidol on the urinary excretion of dopamine, homovanillic and vanilmandelic acids in schizophrenics. Psychopharmacologia (Berl.) 8, 60-66, 1965.

8 ) Bruno, A., Bozzi, R., Allegranza, A. and De Vito, C. : L'eliminazione dei principali metaboliti urinari della serotonina, dopamina, noradrenalina, adrenalina durante trattamento con reserpina e con cloropromazina in soggetti schizofrenini. Riv. Pat. nerv. ment. 84, 451-492, 1963.

9) Bruno, A. and Bruno, S. C. : Effects of LDopa on pharmacological parkinsonism. Acta Psychiat. Scand. 42, 264-271, 1966.

10) Bunney, W.E., Janowsky, D. S., Goodwin, 
F.K., Davis, J. M., Brodie, H.K.H., Murphy, D. L. and ChASe, T.N. : Effect of L-Dopa on depression. The Lancet. April 26, 885, 1969.

11) CARlsson, A. : The occurrence, distribution and physiological role of catecholamines in the nervous system. Pharmacol. Rev. $11: 490-493,1959$.

12) Degkwitz, R., Frowein, R., KuhlenkampfF, G. und MoHS, U. : Über die Wirkungen des L-Dopa beim Menschen und deren Beeinflussung durch Reserpin, Chlorpromazin, Iproniazid und Vitamin $\mathrm{B}_{6}$. Klin. Wschr., 38, 120-123, 1960.

13) Ehringer, H., und HoRnykiewicz, O. : Verteilung von Noradrenalin und Dopamin (3-Hydroxytyramin) im Gehirn des Mens- chen und ihr Verhalten bei Erkrankungen des Extrapyramidalen Systems. Klin. Wschr. 38, 1236-1239, 1960.

14) Gottfries, C. G., Rosengren, A. M. and Rosengren, E. : The occurrence of homovanillic acid in human brain. Acta pharmacol. toxicol. 23, 36-40, 1965.

15) Ingvarsson, C. C. : Orientierende Klinische Versuche zur Wirkung des Dioxyphenylalanins (1-Dopa) bei endogener Depression. Arzneimittel Forsch. 15, 849-852, 1965.

16) Sano, I., Gamo, T., Kakimoto, Y., TaniguChi, K., Takesada, M. and Nishinuma, K. : Distribution of catechol compounds in human brain. Biochim. biophys. Acta. 32 : 586-587, 1959. 